\title{
LPS IMPLEMENTATION USING PHYSICAL AND DIGITAL VISUAL MANAGEMENT- BASED TOOLS: A CASE STUDY IN LUXEMBOURG
}

\author{
Duan Hua ${ }^{1}$ and Thomas Schwartz ${ }^{2}$
}

\begin{abstract}
The Work described in this paper presents the results of a lean construction research project. The objective was to evaluate the impact of Visual Management-based tools to improve Last Planner® System implementation in Luxembourg. To drive this project, a Design Science Research methodology has been used on two construction sites.

The first step of the research focuses on the use of physical supports to design visual management-based tools to implement LPS conversations. The results show a very positive impact as it tackles LPS implementation challenges (collaboration between trades, skills acquisition, change management) but also show that the workload to manage LPS conversation is a serious problem.

The second step of the research tackles this workload issue by digitizing the Visual Management-based tools designed in the first iteration. The results show a huge improvement for users allowing more efficient meetings, better access to data, improved use of LPS outputs to communicate between the client and the project management team and even more flexibility to respect COVID 19 sanitary rules.

The paper concludes with the limit of the digital solution which was used in this project. As it is not specially dedicated to LPS it lacks the possibility to calculate and simulate planning and production data.
\end{abstract}

\section{KEYWORDS}

Last Planner® System, digital, visual management, obeya.

\section{INTRODUCTION}

The Last Planner® System (LPS) is a method for planning and controlling production developed by Ballard and Howell (Ballard and Howell 1994) for the construction industry

It aims to reduce variability and uncertainty in the production workflow by planning, removing constraints and ensuring continuous improvement.

Recent decades have shown that the implementation of LPS is a real issue for construction companies (Porwal et al. 2010). Several challenges as, partial LPS implementation (Bhargav, 2015), lack of training (Fernandez, 2018), issue with change management (Tayeh, 2018) complexity to implement specific discussion, ie make ready

$1 \quad$ R\&D Engineer, Luxembourg Institute of Science and Technology, Luxembourg, duan.hua@list.lu, orcid.org/0000-0002-8793-285X

2 Senior R\&D Engineer, Luxembourg Institute of Science and Technology, Luxembourg, thomas.schwartz@list.lu, orcid.org/0000-0002-1775-0524 
plan (Ebb, 2018) have been reported without giving real operational solutions for LPS practitioners. This paper describes two separate instances of LPS implementation from past and ongoing projects and a presentation of operational tools tackling LPS implementation challenges. As LPS is closely associated with collaboration (Mosmann, 2015), transparency (Brady, 2014), operation tools based on visual management (Brady, 2014) will be presented and evaluated as they could bring an important support for LPS implementation by ensuring more structure and facilitate skills acquisition. In addition, it has been observed that LPS meetings are time consuming (Bassam 2018), to tackle this challenge, an IT based solution will be presented as it could easily provide extra support to facilitate LPS implementation. Evaluations of both implementations will be based on observations and users' feedbacks.

\section{THE LAST PLANNER® SYSTEM}

The Last Planner® System, developed by Ballard and Howell in 1992, focuses construction project management around planning and production control, rather than on directing and adjusting production (Daniel et al. 2015). This method improves collaboration between the different project stakeholders to reach the common goal by organizing / structuring collaboration around 5 conversations (Mossman 2015) with specific goals:

- Should: Master Schedule and Phase Schedule

- Can: Make Work Ready Plan

- Do: Weekly Work Plan

- Did: Percentage of Promises Completed and Continuous Improvement

Studies have reported the substantial benefits resulting from the implementation of the LPS in building construction (Alarcón et al., 2005), which could explain the increasing demand from construction stakeholders, building project owners and contractors. The main barriers to LPS implementation are related to a lack of both training (Fernandez, 2018) and time to implement change management, resulting in an insufficient acquisition of LPS skills from stakeholders. In addition, the complexity of the LPS method and the fact that meetings are considered a waste of time by most subcontractors in our study can result in a loss of interest from participants, drastically reducing the level of collaboration and the added value of the LPS method. This sometimes results in LPS ultimately being abandoned.

\section{RESEARCH METHOD}

Khan 2014, indicates that Design Science Research (DSR) can support the development of valid and reliable knowledge that can be used to create lean solutions to practical problems in the construction industry.

As already done by several lean construction publications, we used a Design Science Research (DSR)methodology both to develop new artefacts to solve issues we faced during our LPS implementation and to contribute to the theory of the LPS (Lukka, 2003).

The Design Science Research methodology (DSR) (Peffers, 2007) adopted for this research required the first five steps to be implemented in order to develop an LPS physical environment with 'paper artefacts' that tackles the problem we faced during past LPS implementations. We've used the DSRM method in a specific manner; we did not perform several iterations on the same problem. To provide practical results we carried 
out one iteration tackling a challenge based on literature review and a second one discovered during the evaluation phase of the first iteration. After the design, the implementation and the evaluation of our demonstrator on the field. The first iteration showed good results for the dynamics of the collaboration, but other additional practical problems appeared. We decided to solve those issues with an IT solution and a second iteration (Fig 1) on a different construction project. Those two iterations will be presented in this paper

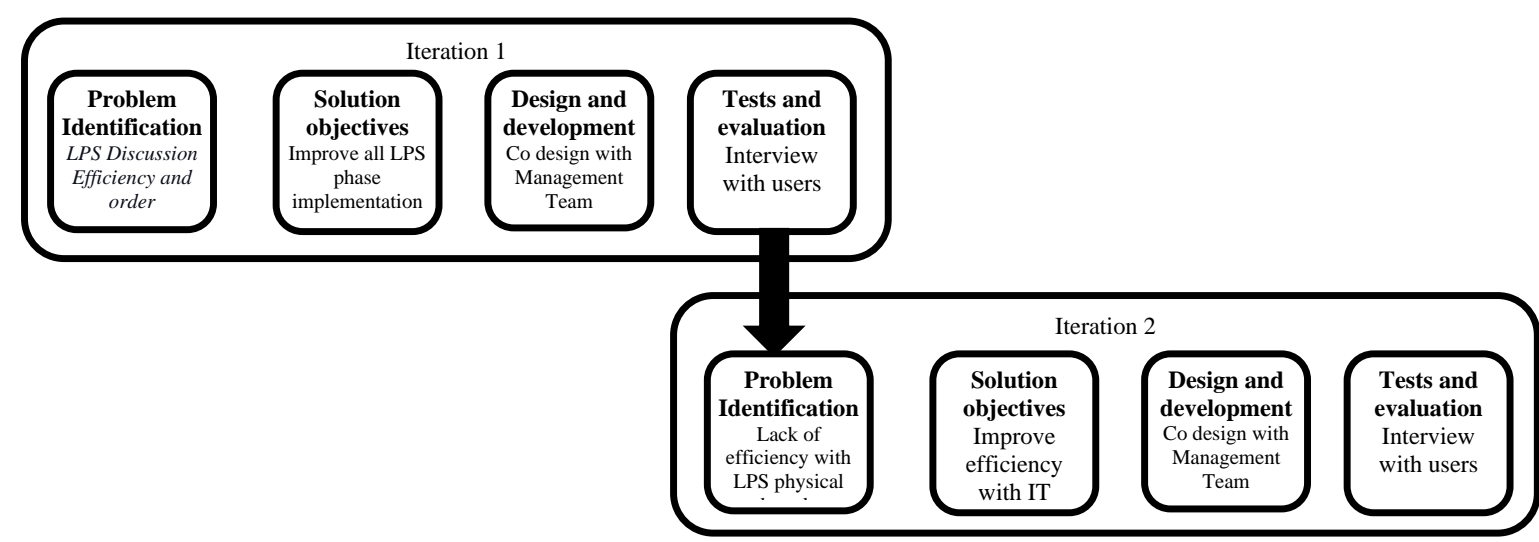

Figure1 Double iteration DSR Scheme

For each iteration, a first explanation on the context and the tools used will be done, then the identification of the practical problems and their impact on the LPS implementation and finally the solution developed and its evaluation on the field.

\section{FIRST ITERATION}

The first iteration of our research was requested by a building owner wanting to implement the Last Planner ${ }^{\circledR}$ System for a $€ 10$ million project that included all building trades. The project stakeholders had no experience with LPS. The project manager was highly experienced in using the classic method based on directing and adjusting (Cybernetic model). All subcontractors and the project manager were trained in LPS concepts and conversations, in the weekly meeting routine, and were trained to use the different physical tools supporting LPS implementation. Several evaluations were planned with the teams to adjust the process and tools according to user needs.

\section{Problem IDENTIFICATION AND MOTIVATION: LPS DisCUSSION EFFICIENCY AND ORDER}

We decided to tackle two practical problems identified during past LPS implementations that were related to one or more LPS implementation challenges already identified in the literature. Mixing LPS discussions leading to partial implementation (Bhargav,2015) and improve Make Ready Discussion (Ebb 2018).

\section{FirST ISSUE ADDRESSED: MiXING LPS Discussions}

It has been observed that most LPS projects were characterized by a lack of training, and a lack of time to manage change. As a result, although users invest time in LPS, they still have a "This is how I "ve always done it" attitude, which results in managing LPS conversations in the wrong chronological order and mixing their objectives, thus leading to partial LPS implementation. As an example, contractors and subcontractors have the 
tendency to start the Make Work Ready Plan too early, extracting data directly from the Master Schedule before working on the Phase Schedule. Without robust information like detailed planning, work sequence or the agreement between subcontractors about consecutive tasks handoffs, investing time in preparing task soundness is highly unproductive, as non-priority tasks will be addressed, and work started too early will have to be done again. Furthermore, these digressions result in a global loss of efficiency, longer meetings that do not produce what is expected, a loss of interest in LPS as the objectives are not achieved, and the risk of giving up on LPS.

\section{Solution Objective}

Compensate lack of training, lack of implementation time available by improving the guiding capacity of supporting tools and improving the "learning by doing" effect provided by visual management (Tezel et al.2009)

\section{Design and Development}

The main element in this proposal for supporting LPS implementation was to guide users with a dedicated physical tool for each LPS conversation. Therefore, sticky note boards have been used to support the Master Schedule (MP) and Phase Schedule (PS) (Fig.2), Make Work Ready plan (MR) and Weekly Work Plan (WWP).

Each tool was designed to fit with each LPS conversation and its objectives with a specific time horizon (monthly for the MP, weekly for the PS and daily for the WWP) and a specific level of information granularity. This helped subcontractors to focus their exchanges during meetings, helped the LPS facilitator to avoid digression, and avoided describing a task in too much detail too early on or planning and preparing a task too late.

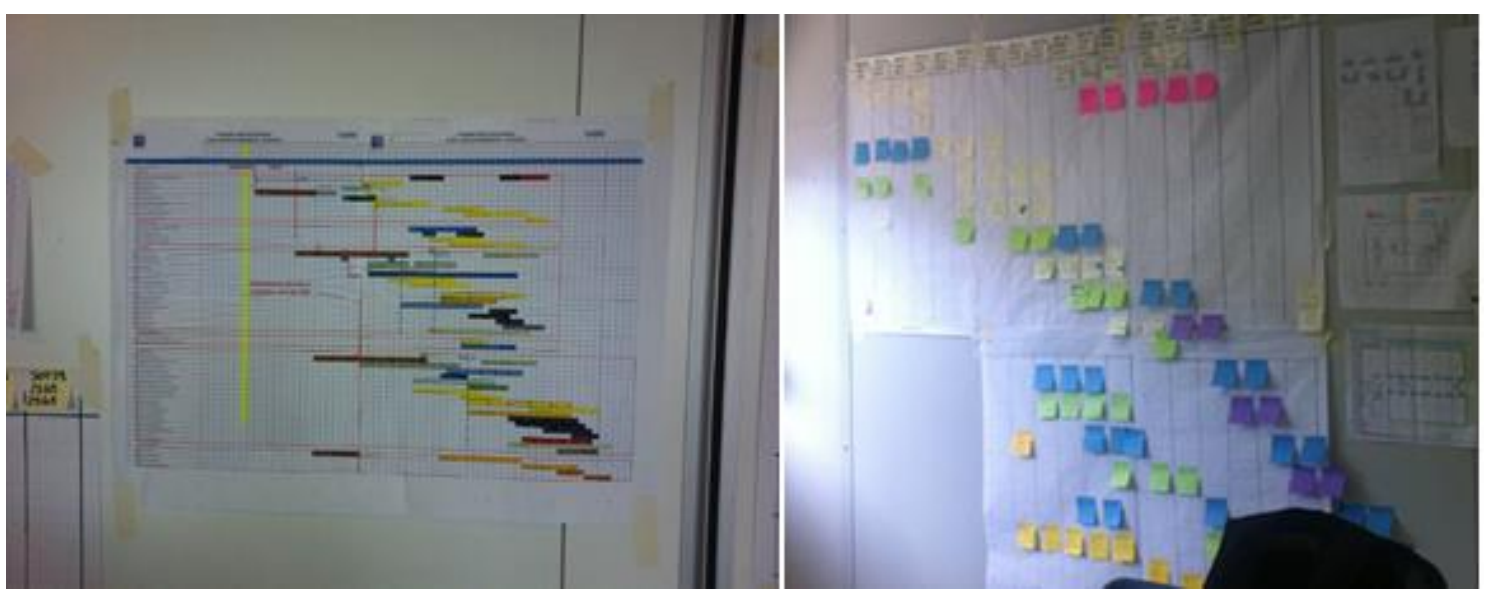

Figure 2: Master Schedule \& Phase Schedule

\section{Tests and Evaluation}

According to observations during meetings and interviews with users, the implementation of a specific visual management-based tool for each conversation enabled the project team to improve its productivity and collaboration during LPS meetings and reduce meeting length by focusing only on the LPS conversation objectives. It also provided a structured routine to manage LPS meetings, and improved stakeholders' involvement and their ability to take responsibility, as well as their autonomy to fuel the meetings with data. The different tools supporting each LPS conversation and their specific design helped users to acquire LPS skills, which resulted in more discipline during the meetings. 


\section{SECOND ISSUE AdDRESSED: IMPROVE THE MAKE READY CONVERSATION}

The second issue was the implementation of the Make Ready conversation as it induces the most important change (Ebbs, 2018) Indeed, for construction stakeholders, solving problems and removing constraints are common activities in a construction project. These used to be accomplished in an individual fire-fighting dynamic rather than in a planned and collaborative way as recommended in the LPS method. It is common to use Excel sheets (Figure 3) to identify and monitor constraints by providing key information like task description, localizations, comments, deadlines for removing the constraints, time horizon, and the person responsible for the constraint removal. However, we found that a simple list was not enough to help people collaborate in identifying constraints and monitoring constraint removal as it is difficult to identify work priorities and task "soundness"(Mossman 2015) issues according to the production horizon.

\begin{tabular}{|c|c|c|c|c|c|c|c|c|c|c|c|c|c|c|c|}
\hline \multicolumn{8}{|c|}{ Task Operationalisation } & \multicolumn{3}{|c|}{ Information } & \multicolumn{4}{|c|}{ Ressources } & \multirow{2}{*}{\begin{tabular}{|l} 
Ready \\
Y/N
\end{tabular}} \\
\hline $\mathbf{N}^{\circ}$ & Task & Description & Zoning & Remark & Week & Date & Responsible & Plans & $\begin{array}{l}\text { Validated } \\
\text { Plans }\end{array}$ & $\begin{array}{l}\text { Auhthoriza- } \\
\text { tion }\end{array}$ & HR & materials & Equipment & Space & \\
\hline 130 & Masonry & Joints for prefab wall & Stairs & & 35 & 29-aug & ASCO & v & v & $\mathrm{v}$ & & & & & \\
\hline 128 & Masonry & Wall boiler room & $\mathrm{LV}+2$ & & 39 & 24-sept & ASCO & v & v & $v$ & v & v & $v$ & v & r \\
\hline 112 & Masonry & $\begin{array}{c}\text { Concreting Elevator Inspection } \\
\text { hatch }\end{array}$ & Roof & $\begin{array}{l}\text { Inpection Hatch } \\
\text { Protection }\end{array}$ & 36 & 05-sept & $\mathrm{ASCO}$ & $\mathrm{v}$ & v & $\mathrm{v}$ & $\mathrm{v}$ & & & & \\
\hline 127 & Masonry & Closing wall roiler Room & $L v+2$ & & 36 & 09-sept & ASCO & v & v & $v$ & & & & & \\
\hline 144 & Masonry & $\begin{array}{l}\text { Finalizing Coincreting disposal } \\
\text { room }\end{array}$ & Basement -3 & & 39 & 24-sept & Asco & v & v & v & v & & & & \\
\hline
\end{tabular}

Figure 3: Make Ready

\section{Solution Objective}

Improve the Make Ready implementation and Collaboration, Support Constraint removal with visual management control.

\section{Design and Development}

A design has been completed with project members to integrate visual management functions to simplify data display (Tezel et al 2009) and ensure learning by doing. This solution was based on a kanban board (Figure 4) to represent task soundness according to different constraint categories (Ballard and Tommelein 2016). Using visual control, this view enables the quick identification of priority tasks with a low level of soundness and short production horizon.

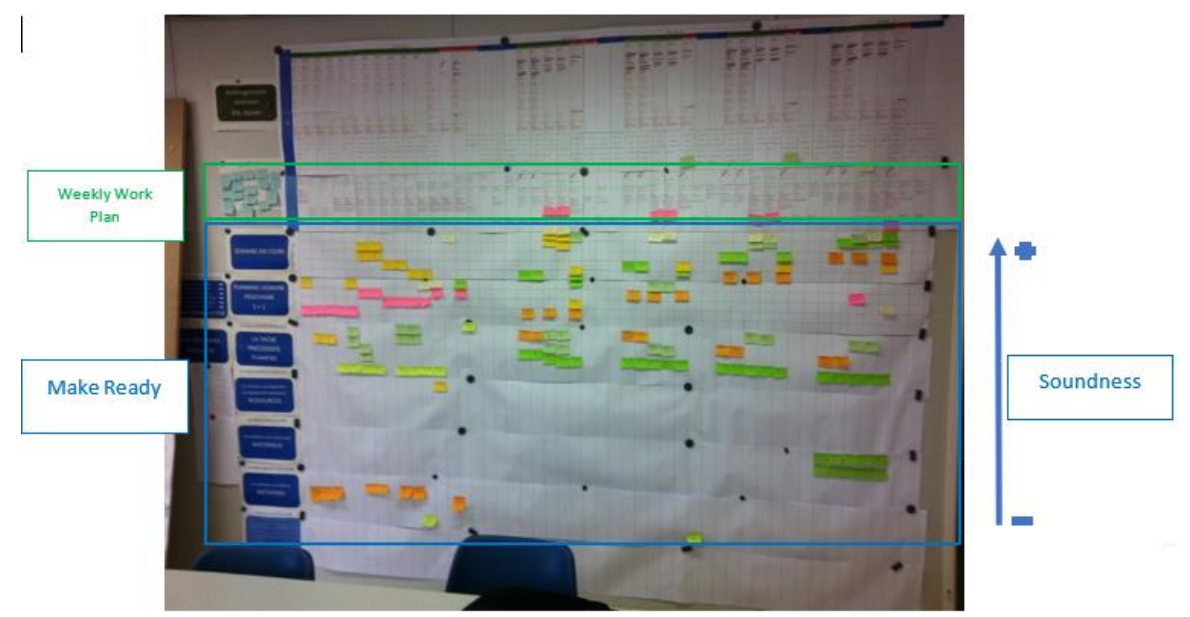

Figure 4: Visual Management-based Make Ready tool Linked to Weekly Work Plan 


\section{Tests and Evaluation}

This tool helped improve the Make Ready conversation by using collective intelligence, and the combined experiences of all trades to define and deal with constraints according to shared resources (space and coactivity, crane time...), settle handoffs between trades, and define options and alternative ways of fulfilling tasks and improving commitment before production.

The final point was the time gain for project managers, as shared planning between several managers and autonomous subcontractors helped the project managers improve their added value by allowing them to focus their workload on anticipating problems and improving collaborative decision-making, rather than firefighting and solving administrative issues.

\section{General Evaluation}

Despite the solutions implemented bringing huge benefits for LPS implementation, several problems were pointed out. The main problem was the time required to produce and update the different views for each conversation. Indeed, planning charts were filled with hundreds of sticky notes that needed to be written out and moved by hand one-byone. In addition, all views needed to be updated by hand from Master Schedule to production plan and vice versa. The question of accessibility was also noted. In practice, physical boards are only accessible in the construction office containers. Furthermore, the use of the planning charts for reporting was complicated as photos were not always exploitable; handwriting also caused some readability issues. All these elements are serious hindrances for LPS implementation and led us to a second iteration with another construction project and a new team. Those challenges will be tackled in the second iteration.

\section{SECOND ITERATION}

Another collaboration project was defined with a general contractor wanting to implement LPS with physical and digital tools on several construction sites. This section will focus on the implementation of a digital visual management-based solution for a project entailing the renovation of an existing building in Luxembourg city centre. Although the project manager had a little experience in the LPS method, the construction manager and his assistant had no experience in LPS before the beginning of the project.

To support the skills acquisition of the project team, several training sessions were planned to transfer LPS concepts, tools and routines, alongside time dedicated to implementation support and coaching for the construction manager and the assistant, who was identified as the future LPS facilitator.

\section{SOFTWARE SELECTION}

Our Company selected software to support our work on visual management-based tools to improve LPS implementation according to our past experiences that led us to identify key issues.

\section{Problem IDENTIFICATION}

Several problems were identified during our first iteration and were solved during this second iteration:

\section{- Reduce time wasted}




\section{- Improve information availability}

- Synchronize all LPS views

- Gain space in construction office containers

\section{REDUCE TIME WASTED:}

Whether for the Master Schedule or Phase Schedule, the initialization of this views requires testing several ways of representing information and formalizing different construction scenarios. Using physical boards for this can take a lot of time due to the number of sticky notes to handwrite and to move. It is sometimes the cause of a chart that no longer represents the reality in the field.

\section{Solution Objective}

Improve data production during meetings.

\section{Design and Development}

The software enables the users to:

- Copy/paste sticky notes that, after few weeks of work, are often the same or just a variation of old sticky notes.

- Adjust planning with the drag-and-drop function.

- Duplicate entire boards or sequences of work to create alternative scenarios.

- Copy data from a low-detail planning to a higher-detail one.

\section{IMPROVE INFORMATION AVAILABILITY:}

Each meeting requires the planning views to be updated based on considering the actual progress of work, changes requested by the client and provisional planning adjustments to respect milestones. Provisional planning updates must be part of the meeting minutes to allow each trade to prepare the next meeting with constraint identification, resource availability, etc. Taking pictures of plannings and send them is not ideal, therefore this solution request additional work to formalize the adjustments made during the meeting. This administrative Works takes time for the lean facilitator to complete, which creates a problem as he/she has less time to prepare and follow up the next meeting.

\section{Solution Objective}

Improve use of administrative time between meetings for all stakeholders.

\section{Design and Development}

The software enables users to export planning charts in a digital format, the project manager to share global planning charts with the client or the client's project manager, and enables specific data to be shared with subcontractors, architects or engineers by sorting data so that it is assigned to a specific user. Furthermore, online access and user access management facilitate the access to planning charts for all stakeholders and allows subcontractors to update their work in the field with an app.

\section{SYNCHRONIZE ALL LPS VIEWS :}

Splitting planning information between several boards is one way to facilitate the structure of LPS conversations and avoid mixing discussions during meetings. However, being able to see / understand the impact of a change in a short-term plan over a more long-term view is crucial to respecting the final deadline. With physical boards displaying 
those LPS views, this link is only made by people, which brings more complexity in terms of ensuring coherence between high-level planning and short-term planning. More importantly, updating the Master Schedule with updated data from the field is a complex exercise. This information flow needs to be explicitly defined in the LPS. (Bhargav et al. 2015).

\section{Solution Objective}

Improve coherence between LPS conversation and its dedicated tools.

\section{Design and Development}

Synchronized and encapsulated sticky note functions enable the synchronization between views and the visualization of a correct level of information according to the LPS conversation. As an example, activities from the Phase Schedule (Figure 5) are described as more detailed tasks in the shorter-term planning horizon, the Look Ahead Plan. Those tasks are then used to facilitate the last planner's commitment in the Weekly Work Plan and are finally archived as soon as tasks are completed and validated (Figure 5). A visual signal is displayed on the Master Schedule every time a synchronized task is moved on the Phase Schedule and vice versa to invite the user to check the impact of a modification in the shorter or longer term.

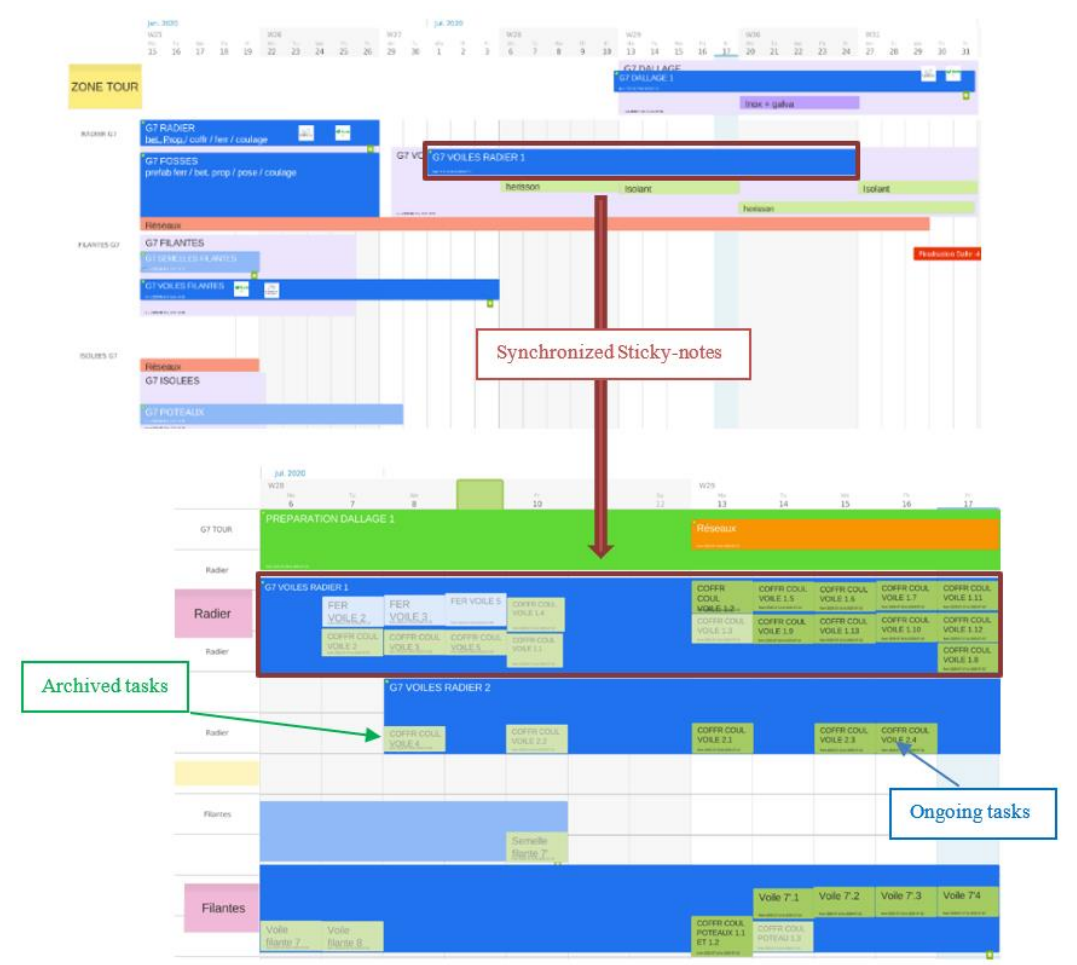

Figure 5: Phase Schedule to Look Ahead Plan to Weekly Work Plan

\section{Gain Space in Construction OfFice Containers}

Using visual management requires a large surface to display information. Depending on the project complexity, a large wall area is required; even if the use of removal panels is possible, the area available to display visual devices is sometimes critical and has a recurring cost. In some cases, these recurring rental costs for extra construction office containers are a hindrance to visual management deployment. Also, to respect COVID- 
19 sanitary measures, it is more complex to organize meetings using common supports and using sticky notes can be tricky.

\section{Solution Proposed}

Improve flexibility and LPS Implementation in the construction office containers.

\section{Design and Development}

Each specific view related to an LPS conversation can be displayed on a large touchscreen $(+65$ ") which allows the reduction of the space requirement. It has been observed that the rental cost of the touchscreen was equivalent to the rental of an extra office. In addition, sometimes the number of office containers is limited.

Another important function is the online multi-user access. The software enables the different subcontractors to contribute to the same document during online meetings with their own IT device, ensuring the respect of COVID-19 sanitary measures and that meetings can be held remotely when mandatory.

\section{General TeSTS AND EVALUATION}

According to the interviews with team members, the use of the software greatly improved efficiency both during and between meetings for all stakeholders. As many stakeholders, especially subcontractors, usually consider meeting a waste of time, gaining time during LPS meetings was a huge game-changer for LPS adoption, helping users to become more autonomous in LPS planning completion.

Furthermore, it provides the ability to instantly communicate planning charts with the client's project manager after a meeting in order to share focused data. The limits of this kind of software, which is not especially designed for the last planner, is that the LPS facilitator must be experienced and be able to design views for LPS conversations.

\section{CONCLUSION AND PERSPECTIVES}

LPS implementation has often been observed as limited because of the low skills acquisition path from the LPS teams and incomplete or incorrect implementation. The reasons for this are a lack of training and time to implement change in an ongoing project, leading to a low return on investment for LPS meetings.

To respect LPS conversations, according to stakeholders feedbacks, it is confirmed that visual management-based tools are the perfect fit to transpose LPS structures and objectives, in order to improve learning by doing and collaboration, simplify LPS work and reduce the duration of LPS meetings. Nevertheless, LPS physical boards can be a serious hindrance to LPS implementation because of the workload related to sticky note management, the limited of the boards and the space required to hang physical boards.

Those limits can be removed with IT solutions. Therefore, IT associated with visual management is a perfect solution for improving LPS implementation. A highly adaptative software will support experienced LPS users in transposing their LPS routine digitally whereas non-experienced users will continue to need support and coaching from LPS experts.

However, IT solutions require more time and even more change management, it will also induce an initial investment and generates a theft issue because of the use of a touch screen.

Our next research will focus on more data-automatic analyses to provide more added value in the generation of scenarios and automatic Percentage of Promises Complete, as 
well as continuous improvement reporting. We will also focus on the change management process as a lot of construction stakeholders are still technology and change resistant.

\section{REFERENCES}

Ballard, G. and Howell, G., 1994. Implementing Lean Construction: Stabilizing Work Flow. Proc. 2nd Ann. Conf. of the Int'l. Group for Lean Construction, Pontificia Universidad Catolica de Chile, Santiago.

Ballard, G., and Howell, G., An Update on Last Planner, 2003, An Update on Last Planner. Lean Construction Institute.

Ballard G., and Tommelein, I., 2016, Current Process Benchmark for the Last Planner System. Available at p2sl.berkeley.edu.

Bhargav D., Juho-Pekka H., Koskela L., 2015, Exploring the recurrent problems in the last planner implementation on construction projects.

Brady, D. A., 2014, Using visual management to improve transparency in planning and control in construction, Doctoral dissertation, University of Salford.

Daniel, EI., Pasquire, C., and Dickens, G., 2015, Exploring the implementation of the last planner® System through IGLC community : Twenty one years of experience, in: Proc. 23th Ann Conf. of the International Group for Lean Construction, Perth, Australia.

Ebbs, P. J., and Pasquire, C. L, 2018, Make Ready Planning Using Flow Walks: A New Approach to Collaboratively Identifying Project Constraints. In: Proc. 26th Annual Conference of the International. Group for Lean Construction, Chennai, India.

Fernández-Solís J, Porwal V, Lavy S, 2018, Guidelines to Address Challenges Faced by Last Planner Users and Implementers at Organizational and Project Levels.

Khan S., Tzortzopoulos P., 2018, Using design research and action research to bridge the gap between theory and practice in lean construction research, In: Proc. 26th Annual Conference of the International. Group for Lean Construction, Chennai, India.

Lukka K., 2003, The constructive research approach, Case Study Research in Logistics.

Mossman A. 2015, Last Planner, Collaborative conversations for predictable design \& construction delivery.

Peffers, K., Tuunanen, T., Rothenberger, M., Chatterjee, S., 2007, A design science research methodology for information systems research, Journal of Management Information Systems.

Porwal V., Fernández-Solís J., Lavy S., Rybkowski Z., 2010, Last planner system implementation challenges, In: Proc. 18th Annual Conference of the International. Group for Lean Construction, Haifa, Israel.

Tayeh, B.A, Al Hallaq, K., Al Faqawil A.H., Alaloul, W.S., and Kim, S.Y.,2018, Success Factors and Barriers of Last Planner System Implementation in the Gaza Strip Construction Industry, The Open Construction and Building Technology Journal.

Tezel, BA., Koskela, LJ., and Tzortzopoulos, P., 2009, The functions of visual management, available at https://usir.salford.ac.uk/10883/. 